\title{
Promoção de comportamentos proativos em reeducandos em processo de reintegração: Um relato de experiência
}

Carmen Amorim-Gaudêncio. Universidade Federal da Paraíba

Karmem Gouveia Correia-de-Oliveira. Universidade Federal da Paraíba

Lucas Felício Gil Braz. Universidade Federal da Paraíba

Valmir Nunes de Figueiredo Filho. Universidade Federal da Paraíba

\section{Resumo}

O presente relato baseia-se em um projeto de extensão universitária da Universidade Federal da Paraíba, realizado com condenados do regime aberto, semiaberto e livramento condicional que trabalham na Secretaria de Estado da Administração Penitenciária e em seus convênios. O trabalho prático de intervenção foi realizado com base nos princípios da Terapia CognitivoComportamental e teve como objetivo proporcionar uma formação continuada através da promoção de comportamentos socialmente adaptados e aperfeiçoamento das relações interpessoais no trabalho. A partir do processo de intervenção, observouse uma implementação de comportamentos pró sociais e diminuição da reincidência criminal.

Palavras-chave: intervenção psicológica; sistema penitenciário; terapia cognitivo-comportamental; relações interpessoais; condenados.

\begin{abstract}
Promoting proactive behavior of convicts in process of social reintegration: An experience report. This report presents results of a university extension project from the "Universidade Federal da Paraiba", performed with convicts serving on open regime, semiopen regime and parole, who are working in the State Secretary for Penitentiary Administration and its covenants. The practical work of intervention was conducted in accordance with the principles of Cognitive Behavioral Therapy, and aimed at providing continued education through the promotion of social adapted behavior and the improvement of interpersonal relationships at work. From the intervention process, it was observed an implementation of pro social behaviors and reduced recidivism.
\end{abstract} Keywords: psychological intervention; prisons; cognitive behavioral therapy; interpersonal relationships; convicts.

\section{Resumen}

Promoción de comportamientos proactivos en condenados en proceso de reintegración social: Un relato de experiencia. El presente relato es fruto de un proyecto de extensión universitaria de la "Universidade Federal da Paraíba", realizado con condenados de segundo y tercer grado o libertad condicional que trabajan en la Secretaria de Estado de Administración de Prisiones y en sus convenios. El trabajo práctico de intervención se realizó fundamentado en los principios de la Terapia Cognitivo-Conductual, y tuvo como objetivo proporcionar una formación continuada mediante la promoción de comportamientos socialmente adaptados y mejora de las relaciones interpersonales en el trabajo. Con la intervención, se observó la implementación de comportamientos pro sociales y disminución de la reincidencia criminal.

Palabras clave: intervención psicológica; prisiones; relaciones interpersonales; terapia cognitivo-conductual; condenados. 


\section{Ilustração do Problema}

A prisão surgiu no fim do século XVIII e início do século XIX, com o principal intuito de servir como meio de punição através do encarceramento. Apesar de se fundamentar na "privação de liberdade", essa medida por si só não tem sido eficaz no processo de reintegração social (Foucault, 1987). É apenas a partir do século XIX que a função da prisão passa a ser designada por terapêutica, recuperação, ato regenerativo, readaptação, ressocialização e reeducação. Anteriormente, a prisão tinha a função exclusiva de punir o delinquente e defender a sociedade de sua presença através do isolamento (Foucault, 2000).

Entende-se que a concepção de reintegração social, considerando sua abordagem sociológica, parte do princípio de que não será possível reintegrar o condenado unicamente por meio do cumprimento da pena. $\mathrm{O}$ intuito da pena em promover tal processo é deficiente, devido às transformações sociais que geram a adoção de políticas contrárias à ideia de reintegração social (Baratta, 2002). A reintegração social não trata de "reeducar" o condenado para que se comporte como desejam outras classes, mas, reinserir o indivíduo na sociedade de forma efetiva, criando mecanismos e condições para que retorne ao convívio social sem consequências negativas, conscientes do sentimento de tornar-se útil não apenas a si mesmo, mas também a sua família e à sociedade. Quando esse processo não ocorre, o resultado tem sido invariavelmente o retorno à criminalidade, ou seja, a reincidência criminal (Shecaira \& Corrêa Junior, 1995). Portanto, o processo de reintegração social não é simples e ao sair do sistema prisional o egresso encontrará poucas oportunidades de trabalho devido ao seu histórico criminal e estigma social (Miguel, 2013). Diante disso, são necessários programas de reintegração social que oportunizem trabalho e educação aos sentenciados, de modo que seja possível oferecer-lhes melhores condições de convívio social.

\section{A Importância do Trabalho na Reintegração Social}

O trabalho é identificado como sendo a melhor forma de estabelecer uma nova relação do preso com a sociedade (Falconi,1998). Entretanto, através do trabaIho os reclusos também se tornam sujeitos às mudanças impostas pela globalização. Neste sentido, os avanços na tecnologia, responsáveis por alterações significativas nas empresas, passam a exigir muito mais de seus trabalhadores, ficando o reeducando prisional em uma vez mais em desvantagem. Aspectos psicológicos e comportamentais têm função importante no processo de desempenho e adaptação ao trabalho. Neste sentido, assertividade, resiliência, comunicabilidade, autocontrole, responsabilidade, adequação, sociabilidade e empreendedorismo são algumas características que representam as constantes exigências do século XXI (Rocha \& Magalhães, 2013).

Segundo Marchezini-Cunha e Tourinho (2010), o comportamento assertivo é "a expressão de sentimentos e ações que facilitam o convívio social, preservando tanto os direitos/interesses do indivíduo quanto os de seu interlocutor" (p. 296). A assertividade envolve, além de outros fatores, um maior contato visual entre os interlocutores, tom de voz audível e uso de afirmações dotadas de segurança, em conjunto com postura corporal, gestos e expressões faciais adequadas. Já o autocontrole, está relacionado à força de vontade, à capacidade de enfrentar situações difíceis para conseguir resistir às tentações, através de um forte controle emocional (Cruz, 2006). Cruz destaca que determinados problemas sociais [violência, abuso de drogas, etc.] se relacionam com déficits em estratégias de autocontrole, reforçando que é "mais um importante instrumento para a resolução daqueles problemas comportamentais que envolvem tanto o interesse dos indivíduos quanto do grupo no qual estão inseridos" (p. 92). A resiliência é outra característica que se relaciona com vários aspectos da vida da pessoa assim como, com trabalho eficaz e desempenho ideal. Trata-se de uma capacidade adaptativa ao estresse e aos processos de recuperação e superação de abalos emocionais. A resiliência pode trazer contribuições importantes para os projetos de intervenção social com indivíduos fragilizados diante de situações conflituosas para fortalecê-los; recuperá-los e torná-los mais resistentes às adversidades (Brandão, Mahfoud, \& Gianordoli-Nascimento, 2011).

Uma inserção social digna pode ser alcançada desde que existam condições apropriadas de educação, saúde e trabalho. Dadas estas condições, é importante que suas relações interpessoais também sejam consideradas (Cunha, 2010). As relações no ambiente de trabalho se constroem a partir do processo de interação entre os membros do grupo como uma ação coletiva para alcançar um objetivo comum. Assim, algumas características individuais tornam-se fundamentais para a existência de relações interpessoais positivas no 
ambiente laboral (Silva, 2002). Nesse contexto, as funções psicointelectuais dos indivíduos são determinantes para o processo de adaptação social (Wagner, Thofehrn, Amestoy, Porto, \& Arrieira, 2009) e, as circunstâncias e as carências dos presos condenados a penas restritivas de liberdade dificultam muito esta adaptação, já o tempo de cárcere não facilita a aquisição de bons hábitos que favoreçam sua volta a uma vida participativa e integrada à sociedade.

\section{A Terapia Cognitivo-Comportamental como Possibilidade de Intervenção}

No contexto internacional a realização de programas de tratamento prisional é uma realidade, principalmente em função dos crimes cometidos. Esse tipo de ação otimiza os recursos (humanos e materiais) viabilizando os bons resultados para a reinserção social. Nesse sentido, os programas comumente mencionados são destinados a crimes que usam a violência, ainda que podem ser aplicados a uma variedade de delitos. Os mencionados programa utilizam-se de diferentes abordagens e podem ser classificados como: a) socioculturais, de caráter psicoeducativo e com um enfoque de gênero, b) cognitivo-comportamentais, com base na teoria da aprendizagem social, c) psicodinâmicos, que incidem sobre aspectos psicopatológicos ou traumáticos relacionado com a dependência e, finalmente, $d$ ) sistémicos, com base nas teorias relacionais (Maiuro \& Murphy, 2009). Entretanto, estudos internacionais sobre evidências dos resultados revelam que independente do tipo de sistema (fechado, semiaberto e aberto) ou do momento da pena (progressão ou regressão) os programas possuem como base prática o modelo de intervenção cognitivo-comportamental, ainda que incorporem diferentes abordagens teóricas no formato. Nesse sentido, todos compartilham elementos comuns e a necessária aceitação da responsabilidade pela violência ou ato criminoso cometido, a empatia e gestão emocional, a reestruturação cognitiva de ideias distorcidas sobre a violência e as mulheres, no caso de agressores de gênero, habilidades sociais, enfrentamento e questões de prevenção e recaídas (Martínez \& Pérez, 2009; Redondo, 1993). Além disso, tiveram que adaptar-se à falta de vontade dos sujeitos, negação do problema, maior incidência de violência psicológica e a necessidade de reavaliar o risco de violência continuamente (Carbajosa \& Boira, 2013; Echeburúa, Sarasua, Zubizarreta, \& Corral, 2009).
O treinamento em determinadas estratégias (TCC) ajuda os indivíduos a centrar-se nos seus problemas, visando a promoção de comportamentos proativos orientados a busca de soluções e tomadas de decisão sobre o ambiente, em benefício de sua adaptação às situações sociais e controle emocional. Na revisão da literatura realizada por Flores (2012) sobre a efetividade da TCC no tratamento psicológico das pessoas com HIV/ AIDS, a autora apresenta em suas considerações evidências de efetividade desta abordagem na aquisição de recursos e estratégias cognitivas e comportamentais que podem ser facilmente utilizadas na redução de sintomas, aumento da autoestima e construção de redes de apoio. No entanto, no contexto nacional, a realização de programas de tratamento com estas características com presos é bastante desconhecida ou talvez inviabilizada devido às circunstâncias de funcionamento do nosso sistema prisional. Ao realizar uma busca nas bases de dados Index Psi (www.bvs-psi.org.br) e Google Acadêmico (2016) com as palavras e/ou expressões-chave "tratamento psicológico prisional" e "intervenção psicológica em prisões" encontrou-se unicamente o plantão psicológico realizado por Guedes (2006) com presas em uma delegacia. A autora atendeu a mulheres que se encontravam presas em um período de um mês a três anos e trabalhou o cotidiano prisional, a maternidade/relações familiares, as vivências amorosas internas/externas e as relações de gênero.

Diante do informado e principalmente, ao considerar a atividade desenvolvida no contexto internacional, considera-se que a prática psicológica estruturada em programas pode auxiliar no fortalecimento ou empoderamento do indivíduo: propicia à pessoa privada de liberdade o conhecimento de suas competências, ajuda-a a apropriar-se do cumprimento de sua pena, a refletir e consequentemente construir seu projeto de vida, além de contribuir para a manutenção e o fortalecimento dos vínculos sociais, familiares e profissionais.

\section{O Que é o Projeto?}

O presente relato de experiência baseia-se em um projeto de extensão intitulado "Promoção de Comportamentos Proativos em Reeducandos que Trabalham na Secretaria de Administração Penitenciária (SEAP)" cujo objetivo foi proporcionar uma formação a presos condenados em regime aberto, semiaberto e livramento condicional que trabalham na SEAP e em instituições conveniadas, colaborando com a reintegração 
social dos participantes e formação dos estudantes envolvidos. Foi desenvolvido durante dois anos consecutivos e, atualmente, ampliado para um Programa de Extensão (PROEXT/MEC/SESU) financiado pelo Ministério de Educação, cujos objetivos são muito mais ousados. Contudo, nos reportaremos exclusivamente ao projeto inicial, objeto desta publicação.

A demanda para a realização do projeto partiu da experiência prática no contexto internacional da coordenadora que recebeu apoio irrestrito da Gerência Executiva de Ressocialização (GER) da SEAP/PB, motivada pelos problemas de adaptação dos presos ao posto de trabalho nos convênios parceiros. Por um lado, havia certa rejeição à presença dos presos e por outro lado, eles se comportavam de maneira inadequada (falta de habilidades no trato social, dificuldade de comunicação, emissão de condutas inapropriadas para a ocasião) fragilizando a parceria.

Após a elaboração do projeto, aprovação da comissão científica, colegiado departamental e do comitê de ética e pesquisa com seres humanos, estruturou-se uma apresentação na SEAP e seus convênios para obter o consentimento de todos os coordenadores das instituições parceiras e definir o planejamento das ações. A participação dos presos foi totalmente voluntária. Nesse sentido, todos os procedimentos éticos foram seguidos de acordo com as normas estabelecidas na Resolução 466/2012 do Conselho Nacional de Saúde. As intervenções eram realizadas na sede da SEAP e em órgãos públicos conveniados com grupos de 10 a 14 integrantes. A duração das sessões era de aproximadamente uma hora para não interferir na rotina das instituições. O número total de sessões por grupo foi de 10 sessões.

Participaram do projeto 42 apenados em situação de progressão de regime [78\% não reincidente e $38 \%$ em regime de livramento condicional], com idades entre 24 e 70 anos ( $M=37$ anos). Do total, $67 \%$ era do sexo masculino, $45 \%$ tinha estado civil solteiro, $36 \%$ possuía o ensino fundamental incompleto, $24 \%$ informou renda familiar de até dois salários mínimos, $76 \%$ não fazia uso de medicamentos no período do projeto e $81 \%$ nunca havia estado com um psicólogo.

Durante a fase de realização do programa, não houve desistência de nenhum dos participantes. No entanto, foram registradas faltas de alguns membros em determinadas sessões. Todos os integrantes estavam em processo de reintegração social, através do trabalho nos convênios e do convívio familiar. A saída do cárcere juntamente com a mudança do cotidiano e a inserção de uma rotina em suas vidas lhes gerava sentimentos de ansiedade e medo de enfrentar às dificuldades de encontrar um novo emprego, após o fim do cumprimento de sua pena e do esperado "desligamento" do trabalho concertado pela GER. Portanto, estes e outros aspectos foram tratados por meio de palestras informativas, treinamento em determinadas estratégias comportamentais e dinâmicas de grupo, com foco na promoção de comportamentos proativos e manejo de situações sociais. Assim como, ensinamentos sobre direitos e deveres com o objetivo de estimular o profissionalismo e aproveitamento de oportunidades. Finalmente, todo o trabalho estava voltado à desconstrução da autoimagem de ser "estranho" e diminuição da reincidência criminal.

\section{A atividade prática}

A recepção do projeto nas instituições parceiras se deu de forma diferenciada. Em alguma houve maior dificuldade de adesão, mas o diálogo construtivo solucionou essa dificuldade inicial e as necessidades da população alvo, foram levadas em consideração.

Na primeira sessão, solicitava-se a participação de cada reeducando assegurando-lhes a voluntariedade, o sigilo e a confidencialidade das informações individuais. Ressaltava-se a importância da execução do projeto, as temáticas que seriam trabalhadas e os objetivos a serem alcançados. Após consentimento dos participantes, realizava-se uma dinâmica facilitadora da interação entre participantes e equipe. Por fim, eram fixados os dias e horários com cada grupo, de forma que os horários estabelecidos não entrassem em conflito com as funções dos participantes nos seus locais de trabalho. Destacava-se neste momento a importância da pontualidade e assiduidade com o compromisso estabelecido.

Na segunda sessão, discutia-se sobre a assertividade. Inicialmente, era exibido o vídeo "Filme da Assertividade" (Costa, 2013) com o objetivo de facilitar o entendimento do conceito e conhecimento dos quatro tipos de comportamentos possíveis (passivo, agressivo, passivo/agressivo, e assertivo). Posteriormente, trabalhavam-se as situações típicas dos participantes fazendo a distinção entre as diferentes formas de comportamento. Destacava-se a importância do comportamento assertivo nos diferentes ambientes e situações da vida cotidiana - casa, trabalho e ambientes públicos. 
Ao final da sessão, Ihes era pedido uma tarefa e que praticassem as estratégias aprendidas.

$\mathrm{Na}$ terceira sessão, inicialmente, pedia-se aos participantes que informassem sobre a tarefa solicitada na sessão anterior. De início, havia pouca participação, entretanto, após algumas falas, os demais começavam a verbalizar suas experiências para o grupo. Posteriormente, apresentavam-se slides contendo definições e observações sobre os quatro tipos de comportamentos - com foco no comportamento assertivo - como reforço ao tratado na sessão anterior. Ao final, perguntava-se sobre as impressões dos participantes. Alguns relatavam sobre a dificuldade de "ter um comportamento assertivo no presídio" e que acreditam que a sociedade espera deles uma conduta "negativa" e "desviante". No final da discussão chegaram à conclusão que deveriam procurar vencer esses obstáculos.

$\mathrm{Na}$ quarta sessão, introduzia-se o tema da resiliência, explicando-Ihes que um indivíduo resiliente é capaz de se recuperar de algum trauma e voltar a condições de normalidade. Comparava-se o indivíduo resiliente a um elástico: "quando se estica um elástico, ele permanece esticado, porém, quando soltamos uma das pontas, o elástico volta ao seu tamanho original". Esta comparação facilitava o entendimento do conceito, e com isso, dava-se prosseguimento à sessão, elencando os cinco pilares da resiliência (autoestima; humor; autonomia; cooperação; e criatividade) e destacando sua importância. Abria-se a discussão para uma participação ativa. Os participantes falavam sobre suas dificuldades pessoais, relatando que em algumas situações também seria difícil "voltar à normalidade", especialmente quando se deparam com obstáculos na construção de sua vida fora do contexto carcerário. A equipe relembrou ao grupo sobre os cinco pilares da resiliência, reafirmando a importância dos mesmos em momentos críticos. Finalizada a sessão solicitava-se a prática do discutido.

Na quinta sessão, trabalhavam-se as dificuldades das relações no trabalho. O preconceito foi relatado como um dos principais obstáculos. Assim, a sessão tinha início com o questionamento sobre a interação dos participantes no ambiente de trabalho diante das críticas. Despois das respostas dos participantes, fazia-se uma seleção daquelas consideradas mais agressivas para trabalhar-se as consequências negativas relacionadas a essa forma de atuar. Destacava-se a perspectiva de que geralmente, não é possível escolher com quem trabalhar e que é preciso saber conviver com as pessoas.
Oportunamente, fazia-se uma diferenciação entre as relações desenvolvidas com o chefe e com os colegas, devendo sempre haver um comportamento cauteloso diante das divergências de opinião. Para finalizar, apresentavam-se sugestões de como desenvolver-se melhor no trabalho e nas relações interpessoais. Abordava-se sobre a empatia, aceitação para com os outros, autoconhecimento, tratar o outro como gostaria de ser tratado, assertividade, etc.

Na sexta sessão, dava-se continuidade ao tema das relações no trabalho, com foco no subtema "postura comportamental" no trabalho. Inicialmente, perguntava-se sobre o conhecimento que tinham sobre o "teatro". Após a emissão das respostas, destacava-se que no teatro para que a peça aconteça cada pessoa tem o papel de colaborador. Fazia-se uma comparação entre o teatro e o ambiente do trabalho, no qual cada um deveria ter um papel de colaborador, fazendo aquilo que the compete e ajudando aos colegas da melhor forma possível. Prosseguia-se com a apresentação de alguns comportamentos que todos, supostamente, deveriam emitir em situações da vida cotidiana e especialmente, no ambiente de trabalho. Apresentavam-se como comportamentos importantes a pontualidade e o planejamento das tarefas em determinado dia de trabalho. Outros comportamentos debatidos foram a assiduidade, a importância da saúde e da higiene, o uso de fardamento e o respeito aos intervalos. Por fim, abordava-se acerca dos procedimentos para uma adequada entrada e saída de um local: abordagem (bater na porta, por exemplo), saudação aos sujeitos presentes, pedido (caso necessite falar com alguém) ou informação, agradecimento ao tempo disposto e despedida.

A sétima sessão tratava sobre autocontrole emocional, levando em consideração o relato dos participantes a respeito das críticas que recebiam, assim como os diversos acontecimentos no cotidiano de suas vidas. Ressaltava-se que o autocontrole envolve o reconhecimento, aceitação, escolha e gerenciamento do que sentimos durante as diversas situações que vivenciamos. Foram apresentadas e discutidas formas de alcançar o autocontrole [respeitar o seu limite, usar um sistema de recompensas ou de penalidades, controlar suas expectativas, ajustar valores e emoções, fazer afirmações e pensar de forma abstrata] buscando sempre o porquê de determinada ação. Em cada um desses pontos, os participantes citavam exemplos de acontecimentos de suas vidas e ressaltavam a importância de tais ações para uma vida melhor. 
Na oitava sessão, discutia-se sobre a valorização do trabalho. Iniciada a sessão, os participantes eram convidados a montar uma lista de respostas para a questão "Por que trabalhar?". As respostas emitidas eram compatíveis com os pontos programados para discussão como que o trabalho é importante; porque é uma forma utilizada pelas pessoas para se sentirem úteis; proporciona a inserção social; possibilita a dignidade; ajuda na consecução de objetivos e cumprimento de responsabilidade, além de oferecer recursos financeiros para suprir as necessidades das pessoas. Durante o encontro, o "trabalho" era tratado como uma atividade que proporciona orgulho e satisfação, e faz parte do caráter e identificação de cada pessoa, dando ao indivíduo diversas oportunidades de crescimento. Ao final da sessão, eram expostos os direitos e deveres dos participantes, perante sua família, as pessoas com que trabalham e toda a sociedade.

A partir das discussões e temas elencados pelos participantes nas intervenções, o tema da nona sessão foi sobre resolução de problemas. Na tentativa de debatê-lo de forma adequada à linguagem dos participantes, fez-se o uso de uma situação-problema, demonstrando as diversas etapas que devemos seguir para que determinado problema seja solucionado de maneira positiva. À medida que tais etapas eram apresentadas, alguns participantes citavam episódios de suas vidas nos quais pensavam não haver saída, porém chegaram a conclusão que eram necessárias paciência e reflexão para se chegar a uma solução mais adequada. Finalizada a sessão, era exposto um pequeno esquema que resumiu as seis etapas discutidas [situação, identificação do problema, investigação, projeto, realização, avaliação].

Na décima sessão, sessão de fechamento, fazia-se uma recapitulação do visto até o momento e se insistia sobre a necessidade de praticar tudo para não esquecer. Os participantes falaram de maneira geral sobre a importância de terem participado do projeto. Por fim, eram entregues os certificados de participação, fato que lhes proporcionava certa satisfação. Em um dos convênios parceiros, os participantes ofereceram uma festa de despedida à equipe como forma de agradecimento pelos ensinamentos, fato emocionante para os executores do projeto.

\section{Considerações finais}

A partir da intervenção realizada pôde-se observar o crescimento dos reeducandos através da participação ativa nas sessões. Por outro lado, a Gerencia Executiva de Ressocialização, responsável pelo acompanhamento dos presos, informou sobre a ausência de reincidência criminal dos participantes durante os meses subsequentes a realização do projeto. Este fato proporcionou a redução dos pedidos de substituição de presos por parte das instituições parceiras e adesão do convenio. Acredita-se, portanto, que a execução do projeto foi de grande importância para este grupo de presos no momento de sua reintegração social. Neste sentido, corroborando com outros autores, destaca-se a importância da dedicação às atividades extensionisas nessa área, tendo em vista a mudança social benéfica que pode acontecer em meio as adversidades existentes no âmbito prisional (Guedes, 2006; Pires, 2013; Santos \& Fedeger, 2008).

Finalmente, ofereceu-se uma oportunidade de serem repensadas novas formas de intervenção com presos, a modo do que vem ocorrendo no contexto internacional (Geldschläger et al., 2010), apesar da falta de infraestrutura de nossas prisões. Talvez, justamente, por estas circunstâncias sejam necessárias ações desse tipo. Especificamente, no que se refere ao processo de reintegração social da pessoa privada de liberdade, propõe-se atuações mais amplas do que aquelas que beneficiam aos presos apenas com o emprego temporário e com a educação formal. Neste aspecto, a literatura internacional tem insistido sobre a necessidade de desenvolver habilidades e estratégias psicológicas e comportamentais com presos como forma de favorecer a reintegração social e consequentemente, contribuir para a diminuição da reincidência criminal.

Adicionalmente, este projeto proporcionou a integração da teoria com a prática psicológica, melhorando o nível de conhecimento e aprendizado dos alunos, na busca de soluções práticas para problemas sociais importantes.

\section{Referências}

Baratta, A. (2002). Criminologia crítica e crítica do direito penal: introdução à sociologia do direito penal (J. C. dos Santos, Trad.) Rio de Janeiro: Revan/Instituto Carioca de Criminologia.

Brandão, J. M., Mahfoud, M., \& Gianordoli-Nascimento, I. F. (2011). A construção do conceito de resiliência em psicologia: discutindo as origens. Paidéia, 21(49), 263-271. doi: 10.1590/ S0103-863X2011000200014

Carbajosa, P., \& Boira, S. (2013). Estado actual y retos futuros de los programas para hombres condenados por violencia de género en España. Psychosocial Intervention, 22, 145-152. Recuperado de http://www.redalyc.org/articulo.oa?id=179828053008 
Promoção de comportamentos proativos em reeducandos em processo de reintegração: Um relato de experiência

Costa, S. (2013, 15 de novembro) Filme da assertividade [Arquivo de vídeo]. Recuperado de https://www.youtube.com/ watch?feature $=$ player_detailpage $\& v=7 w j \mathrm{~Hz} 6 \mathrm{Xa}$ _iQ

Cruz, R. N. (2006). Uma introdução ao conceito de autocontrole proposto pela análise do comportamento. Revista Brasileira de Terapia Comportamental e Cognitiva, 8(1), 85-94. Recuperado de http:// www.usp.br/rbtcc/index.php/RBTCC/article/view/24

Cunha, E. L. (2010). Ressocialização: o desafio da educação no sistema prisional feminino. Cadernos CEDES, 30(81), 157-178. doi: 10.1590/S0101-32622010000200003

Echeburúa, E., Sarasua, B., Zubizarreta, I., \& Corral, P. (2009). Evaluación de la eficacia de un tratamiento cognitivo-conductual para hombres violentos contra la pareja em un marco comunitario: una experiencia de 10 años (1997-2007). International. Journal of Clinical and Health Psychology, 9, 199-217. Recuperado de http:// www.redalyc.org/articulo.oa?id $=33712028001$

Falconi, R. (1998). Sistema Presidial: reinserção Social? São Paulo: Ícone.

Flores, C. A. (2012). Terapia cognitivo-comportamental e tratamento psicológico de pacientes com HIV/AIDS. Revista Brasileira de Terapias Cognitivas, 8(1), 55-60. Recuperado de http://pepsic.bvsalud.org/scielo.php?script=sci_arttext\&pi$\mathrm{d}=\mathrm{S} 1808-56872012000100008 \&$ Ing=pt\&tIng=pt.

Foucault, M. (1987). A Arqueologia do saber. Rio de Janeiro: Forense-Universitária.

Foucault, M. (2000). Vigiar e punir: nascimento da prisão. Petrópolis: Vozes.

Geldschläger, H., Beckmann, S, Jungnitz, L., Puchert, R., Stabingis, A. J., Dully, C., ... Schweier, S. (2010). Programas Europeos de Intervención para Hombres que Ejercen Violencia de Género: Panorámica y Criterios de Calidad. Psychosocial Intervention, 19(2), 181-190. Recuperado de http://scielo.isciii.es/scielo.php?script=sci_ arttext\&pid=S1132-05592010002200009\&lng=es\&tlng=es

Guedes, M. A. (2006). Intervenções psicossociais no sistema carcerário feminino. Psicologia: Ciência e Profissão, 26(4), 558-569. Recuperado de http://pepsic.bvsalud.org/scielo.php?script=sci_arttext\&pid=S1414-98932006000400004\&lng=pt\&tIng=pt

Maiuro, R., \& Murphy, C. (Orgs.). (2009). Motivational interviewing and stages of change in intimate partner violence. Springer Publishing Company.

Marchezini-Cunha, V., \& Tourinho, E. Z. (2010). Assertividade e autocontrole: interpretação analítico-comportamental.
Psicologia: Teoria e Pesquisa, 26(2), 295-304. doi: 10.1590/ S0102-37722010000200011

Martínez, M., \& Pérez, M. (2009). Evaluación criminológica y psicológica de los

agresores domésticos. Barcelona: CEJFE. Recuperado de http:// www20.gencat.cat/docs/Justicia/Documents/ARXIUS/SC-3-160-

09_cas.pdf

Miguel, L. M. S. (2013). A norma jurídica e a realidade do sistema carcerário brasileiro. Revista Habitus, 11(1), 49-64. Recuperado de http:// www.habitus.ifcs.ufrj.br/index.php/ojs/issue/view/15/showToc

Pires, S. R. A. (2013). Sobre a prática profissional do assistente social no sistema penitenciário. Textos \& Contextos, 12(2), 361-372. Recuperado de http://revistaseletronicas.pucrs.br/fass/ojs/index. php/fass/article/view/13614

Redondo, S. (1993). Evaluar e intervenir en las prisiones. Análisis de conducta aplicado. Barcelona: P.P.U. (Univérsitas 30).

Resolução 466/2012, de 12 de dezembro de 2012 (2012, 12 de dezembro). Dispõe sobre as diretrizes e normas regulamentadoras de pesquisas envolvendo seres humanos. Brasília, DF: Conselho Nacional de Saúde. Recuperado de http://conselho.saude.gov.br/ resolucoes/2012/Reso466.pdf

Rocha, M., \& Magalhães, S. R. A. (2013). Jovialismo, resiliência, assertividade: aspectos relevantes no ambiente corporativo. Revista da Universidade Vale do Rio Verde, 10(1), 306-314. doi: 10.5892/ ruvrv.2013.111.306314.

Santos, D. R., \& Fedeger, A. M. (2008). O terapeuta ocupacional no processo de ressocialização de adolescentes em conflito com a lei privados de liberdade: transformação através da ocupação. Revista de Terapia Ocupacional da Universidade de São Paulo, 19(2), 100107. doi: 10.11606/issn.2238-6149.v19i2p100-107

Shecaira, S. S., \& Corrêa Júnior, A. (1995). Pena e Constituição. São Paulo: Revista dos Tribunais.

Silva, M. (2002). Desenvolvendo as relações interpessoais no trabalho coletivo de professores. In L. R. Almeida \& V. M. N. S. Placco (Orgs.), As relações interpessoais na formação de professores (pp. 79-90). São Paulo: Edições Loyola.

Wagner, L. R., Thofehrn, M. B., Amestoy, S. C., Porto, A. R., \& Arrieira, I. C. O. (2009). Relações interpessoais no trabalho: percepção de técnicos e auxiliares de enfermagem. Cogitare Enfermagem, 14(1), 107-113. doi: 10.5380/ce.v14i1.14123 
Carmen Amorim-Gaudêncio, Doutora em Psicologia pela Universidade Complutense de Madri (UCM), é Professora Adjunta no Departamento de Psicologia, Universidade Federal da Paraíba (UFPB) e Coordenadora do Laboratório de Avaliação e Intervenção

Clínica Forense (LAICF/UFPB/CNPq).

Endereço para correspondência: Laboratório de Avaliação Clínica

Forense (LAICF), Universidade Federal da Paraíba, Centro de

Ciências Humanas Letras e Artes - Campus I, Departamento de

Psicologia. Conjunto Humanístico - Bloco IV - Cidade Universitária 58059-000 - João Pessoa (PB).

Telefone: (83) 996754045.

E-mail: camorimg@gmail.com

Karmem Gouveia Correia-de-Oliveira, Graduada em Psicologia pela Universidade Federal da Paraíba (UFPB), é Psicóloga do Serviço de Atenção Domiciliar (SAD).

E-mail: karmen_gouveia@hotmail.com

Lucas Felício Gil Braz, Graduado em Psicologia pela Universidade Federal da Paraíba (UFPB), é Psicólogo colaborador do Laboratório de Avaliação e Intervenção Clínica Forense (LAICF).

E-mail: brazflucas@gmail.com

Valmir Nunes de Figueiredo Filho, Graduado em Psicologia pela Universidade Federal da Paraíba (UFPB), é Psicólogo colaborador do Laboratório de Avaliação e Intervenção Clínica Forense (LAICF).

E-mail: vnunesff@gmail.com

Recebido em 13.Nov.14

Revisado em 23.Set.16

Aceito em 26.Abr.17 